to put aside the first roo papers and to begin marking the fresh papers on such different lines as would, in his judgment, produce an approximation to the normal curve. On the supposition that he had achieved that result for the second roo, and continued to find that his curve was pretty constant for the third 10o, fourth 100, and so on, he was asked at the end of all the papers to re-mark the first Ioo.

You might imagine that many examiners disliked having to place themselves upon this bed of Procrustes, but in the generality of cases it was not so. They positively took a delight in examining themselves. The process became one of self-education in marking.

Before leaving this part of my subject I should like to warn you that certain causes, which an examiner cannot always control, may make it difficult to obtain such an ideal curve as I have shown. It is not possible for me to enter fully into this part of the subject, but I will point out one cause at least that he can control-1 mean the examination paper.

Good marking will not compensate for a bad paper. Every candidate must have his chance, in some question or other. Otherwise the examination is like a hurdle-race in which the hurdles are so high that a considerable number of candidates find themselves stopped from reaching the goal at all. The curve, in such a case, tends to assume a shape of this kind, mounting very rapidly to the zero line (Fig. 5)-just the curve, in fact, which we have already seen in connection with a dictation paper. In this case it is not the marking which is wrong, but the examination paper.

Accordingly, I found in practice that it was necessary to point out to examiners, before ever their papers were proposed in manuscript, that they ought to divide their questions roughly into (say) three portions, of which one portion could be answered by candidates of inferior power, a second should be within the range of mediocre candidates, and a third only possible to candidates who might be classed as good to excellent. The result of these directions was that ex-

Number of marks gained.

Fig. 5. -Dictation Paper.

aminers soon found little difficulty in spreading out their candidates in the desired way. In setting their questions they had before their eyes the little gendarme's hat.

Among the causes, beyond the control of the examiner, which may interfere with the formation of this curve, we must reckon as in the first rank:-(r) such a small number of candidates as does not give fair play to the law of probabilities; (2) any selection of candidates by a preliminary examination or other means.

With regard to the causes just named, I will only say that it has been found that the method can be applied successfully when there are not less than one hundred candidates, and that even below this number, the curve, though irregular in formation, gives us very useful information as to an examiner's capacities. With regard to the second cause, a great deal can be done to produce a satisfactory curve by setting such questions in the further papers as are only addressed to the candidates who remain after the preliminary sifting.

I trust that $I$ have now fulfilled the promise with which I started, namely, to show you how examiners themselves may be examined; and not only this, but you will understand that it is possible to educate examiners so as to enable them to form a much more accurate and sustained judgment of a large number of candidates than would have been within their power without such preliminary guidance.

$$
\text { NO. } \left.180_{3} \text {, VOL } 70\right]
$$

\section{THE CHEMICAL REGULATION OF THE} SECRETORY PROCESS.'

THE researches which we wish to bring briefly before the

Royal Society deal with the mechanism of adaptation to changes in the food and the chemical correlation of the activities of different organs engaged in the digestion and assimilation of the food.

According to Pawlow, the secretion of the pancreatic juice is exactly comparable to the secretion of saliva, and is effected by a nervous reflex. The starting point of this reflex is the stimulation of the duodenal mucous membrane by the chyme, or by substances such as oil, ether, or oil of mustard. Not only is the pancreatic juice turned out into the intestine just at the time when it is required, but, according to Pawlow, the composition of the juice varies according to the food, the proteolytic ferment being increased by a diet of meat, while the amylolytic ferment is increased by a starchy diet. This adaptation of the glandular activity was ascribed by him to a species of "taste" in the mucous membrane. It was imagined that the different constituents of the food excited different nerve endings, which, in their turn, caused reflex activity of different mechanisms in the pancreas itself. The field of these assumed reflexes was considerably narrowed by the researches of Popielski (Gazette Clinique de Botkin, 190o) and Wertheimer (Journal de Physiologie, vol. iii. p. 335 , I90I), who showed that the introduction of acid into the duodenum was productive of secretion even after destruction of all nerve connections of the pancreas and alimentary canal with the central nervous system, and even after extirpation of the sympathetic ganglia of the solar plexus. It was with a view to determine the mechanisms of this reflex secretion of the pancreas, as well as of the adaptation of the pancreatic secretion to variations in the food of the animal, that we began our researches.

The last named authors had also shown that the secretion occurred, but in smaller quantities, if the acid was inserted in any part of the small intestine, with the exception of the lower end of the ileum. It was thus easy to examine the effects of the introduction of acid into a loop of ileum in which all nerve connections with the pancreas, or with the rest of the body, had been destroyed. This crucial experiment had, curiously, not been performed by previous workers in the subject. On carrying it out, we found that destruction of all nerve connections made no difference to the result of introducing the acid. The pancreatic secretion occurred as in a normal animal. It was therefore evident that we had to do here with a chemical rather than a nervous mechanism. Previous work had narrowed the question down to such a degree that the further steps were obvious. We knew already that the introduction of acid into the blood-stream had no influence on the pancreas; hence the acid introduced into the intestine must be changed in its passage to the blood-vessels through the epithelial cells, or must produce in these cells some substance which, on access to the blood stream, evoked in the pancreas a secretion. This was found to be the case. On rubbing up the mucous membrane with acid, and injecting the mixture into the blood-stream, a copious secretion of pancreatic juice was produced. It was then found that the active substance which we call secretin, was produced by the action of acid from a precursor in the mucous membrane, probably in the epithelial cells themselves. Once formed by the action of acid, it could be boiled, neutralised, or made alkaline, without undergoing destruction. The precursor of the substance (pro-secretin) cannot be extracted by any means that we have tried from the mucous membrane. Even after coagulation of the mucous membrane by heat or alcohol, however, secretin can still be extracted from the coagulated mass by the action of warm dilute acid.

We have not yet succeeded in determining the chemical nature of secretin though we have obtained chemical evidence which will serve to exclude certain classes of substances. Thus the fact that it will stand boiling shows that it is neither a coagulable proteid nor a ferment. It is soluble in 90 per cent. alcohol in the presence of ether, but it is insoluble in absolute alcohol and ether. It is slightly diffusible through animal membranes. It can be

1 Abstract of the Croonian Lecture. By Dr. W. M. Bayliss, F.R.S., and Prof. E. H. Starling, F.R.S. Read before the Royal Society, March 24. 
filtered through a gelatinised Chamberland filter. It is not precipitated by tannic acid, thus excluding bodies of alkaloid nature as well as diamido-compounds. This evidence, slight though it is, points to secretin being a body of relatively small molecular weight and not a colloid. It may be compared to the active principle of the suprarenal glands, adrenalin, which has been obtained in a crystalline form and the chemical constitution of which has been approximately determined. This is, indeed, what one would expect of a substance which has to be turned out into the blood at repeated intervals in order to produce in some distant organ or organs a physiological response proportional to the dose. The bodies of higher molecular weight, such as the toxins, which owe their activity, according to Ehrlich, to the fact that they can be directly assimilated by the cells of the body, and built up into the protoplasmic molecule, always give rise to the production of anti-bodies, a process which, while not preventing necessarily their utilisation in the body, would prevent their acting as a physiological stimulus to certain definite cells. Adrenalin and secretin on the other hand belong to the class of drugs which act by their physicochemical properties, and the physiological effect of which is determined by the total configuration of their molecule. It was suggested to us early in our experiments that the secretion of pancreatic juice, evoked by secretin, was essentially a sudden production of an antibody; such a sudden production is unknown in the animal body, and the anti-character of the secretion is at once negatived by the fact that secretin can be mixed with a freshly secreted juice without in any way destroying its efficiency.

Like adrenalin, secretin is extremely easily oxidised, and it is probable that it is got rid of in this way from the body, since, even after repeated injections of secretin, it is impossible to find this substance or any precursor of it either in the pancreas, the urine, or other tissues of the body. Just as in the case of adrenalin, so we find that secretin is not specific for the individual or species. An extract of the mucous membrane of the dog will evoke secretion in the pancreas of the frog, the bird, rabbit, cat, or monkey. In the same way the pancreatic secretion of the dog can be excited by injection of secretin prepared from the intestine of man, cat, monkey, rabbit, fowl, salmon, skate, frog, or tortoise. The evolution of this mechanism is, therefore, to be sought at some time anterior to the development of vertebrates.

The action of secretin is not confined to the pancreas. It has long been known that the pancreatic juice, in order to exert its full activity on the food stuffs, needs the simultaneous presence of bile, and the fact that in many cases the two fluids are poured into the duodenum by a common orifice shows the close connection which must exist between them. Digestion of fats is impossible unless both fluids have access to the gut, and even in the digestion of carbohydrates, as was shown by S. Martin and Dawson Williams many years ago, the presence of bile greatly hastens the digestive powers of the pancreatic juice. Whenever, therefore, a secretion of pancreatic juice is required, a simultaneous secretion of bile is also necessary. It is interesting to note that this simultaneous secretion is provided for by the same mechanism by which the secretion of pancreatic juice is evoked. If the flow of bile be determined by measuring the outflow from a cannula placed in the bile duct, it will be found that introduction of acid into the duodenum causes a quickened secretion of this fluid. The same increase in the secretion of bile can be produced by injecting solutions of secretin into the blood stream. This influence of secretin on the liver has been fully confirmed by Falloise. This observer has shown that acid extracts of the intestinal mucous membrane cause an increase in the bile secretion most marked when the extract is made from the duodenum and diminishing as the extract is taken from the lower parts of the gut, that from the lower section of the ileum being quite ineffective.

The discovery of secretin has placed in the hands of physiologists the power of controlling the activity of a gland by purely physiological means, and we have taken opportunity of the control thus acquired to investigate the exact character of the changes induced in the pancreas under this physiological stimulus. So far as we can tell secretin has no specific influence on any one constituent of the pancreatic

No. 1803 , voL. 70$]$ juice. When injected it causes secretion of a juice which is normal in that it resembles the juice secreted on entry of food into duodenum, and contains a precursor of trypsin, amylopsin, and steapsin. Secretin, in fact, appears to cause the pancreatic cells to turn out the whole of the mesostates which they have accumulated during rest in preparation for the act of secretion. If secretin be injected at repeated intervals until the gland will no longer respond to the injection, it is found on microscopic examination that the cells have discharged the whole of their granules. In sections stained with toluidine blue and eosin the whole of the cells stain blue in marked contrast to the normal resting gland, where one-half or two-thirds of the inner margin of the cells is taken up with brilliantly stained red granules. This effect is not produced in all cases. In some animals we have injected secretin at frequent intervals over a period of eight hours, and obtained at the end of the experiment a secretion as vigorous as after the first injection. The pancreas in this case was evidently not fatigued, and on killing the animal and examining this organ microscopically it was found to give the typical picture of a resting pancreas. One may say, therefore, that under healthy conditions the activity of the pancreas is two-fold in character, and that the normal stimulus of secretin excites not only a breaking down of the protoplasm and a discharge of granules, but also a building up of the protoplasm and a new formation of granules. So marked, in fact, is this power of selfrestitution that it is often advisable to diminish the resistance of the animal by bleeding or other means if it is desired to obtain a specimen of exhausted gland.

A study by Mr. Dale of the stages of exhaustion carried out in this way has brought to light a remarkable behaviour in the cells of the pancreas, to which we have no analogies in other secreting glands of the body. After the discharge of the granules the cells seem to undergo a still further involution, losing the whole of their chromophile substance, diminishing in size or undergoing vacuolation, and finally being transformed into cells undistinguishable from those which have long been known as forming the so-called "islets of Langerhans." Mr. Dale has, in fact, shown that in all probability these "islets," which are generally regarded as pre.formed structures, really represent stages in the functional activity of the secreting cells of the gland, and he is of opinion that the activity of the gland is always associated with a cycle of changes in which the islets are formed, to be afterwards regenerated into secreting tissue. Other observers have noted in the embryo a development of secreting tubules from tissue undistinguishable from the "islets of Langerhans," and it is interesting to note that the depletion of the gland caused by long starvation has a similar effect to that caused by over-excitation, namely, the conversion of a large proportion of the gland tissue into " islet" tissue.

So far we have dealt only with the correlation of the activities of the cells lining the intestinal tube with those forming the masses of the pancreas and liver, and have seen that a very large part in this correlation is played by a chenical substance which acts, so to speak, as a chemical messenger between these various organs. A striking feature, however, of the pancreas is its alleged power of adapting its secretion to the nature of the food taken in by the animal. It has been stated by Pawlow that according as the food consists chiefly of proteids, carbohydrates, or fats, so do we find a relative preponderance of the ferments acting respectively on each of these three classes of foods. The evidence on which this statement is based, although lending to it considerable support, is not absolutely convincing. Vasilieff (Archives des Sciences Biologiques, St. Petersburg, I893) examined the pancreatic juice of dogs which were fed on meat, or bread and milk alternately for periods extending over several weeks for each kind of diet. This observer found that the transition from bread and milk diet to a meat diet caused a rapid rise in the proteolytic power of the juice, which reached its maximum after several days of meat feeding. A return to a diet of bread and milk caused a slower fall in the proteolytic power of the juice, but a rise in the amylolytic power. Similar results were obtained by another pupil of Pawlow-Jablonsky (ibid. I896) - who also extended his observations to the fat-splitting ferment. At the time that these observations were made the function of enterokinase was unknown, and it is there- 
fore impossible to say what proportion of the trypsinogen of the juice secreted in these experiments had been converted into trypsin by the small amount of intestinal mucous membrane at the mouth of the duct. While, therefore, we are unable to ascribe much importance to the results as regards the proteolytic power of the juice, there seems no reason to doubt the results obtained by these workers as regards the starch-digesting power of the juice. In 1899 Walther (ibid., I899, vol. vii. p. I) made a series of observations on a dog with pancreatic fistula in order to determine whether the amounts of ferments secreted were determined by the nature of the food at any given meal. He was satisfied that his results showed that, even without prolonged adherence to one diet, the composition of pancreatic juice was adapted to the nature of the meal taken. His results do not entirely bear out his contentions, as is seen by the following table, in which it will be noticed that although milk contains no starch, it evokes the secretion of a large amount of amylopsin, and that meat causes a secretion of more steapsin than does milk, although this latter contains much more fat than the meat diet.

TABLE I.-Results of Walther's Experiments.

\begin{tabular}{|c|c|c|c|}
\hline \multirow{2}{*}{ Diet } & \multicolumn{3}{|c|}{ Total amount of enzyme secreted } \\
\hline & Proteolytic & Amylolytic & Fat-splitting \\
\hline $\begin{array}{l}600 \text { c.c. milk } \\
250 \text { gra ms bread } \ldots \\
\text { I00 grams meat } \ldots\end{array}$ & $\begin{array}{l}1044 \\
2360 \\
1720\end{array}$ & $\begin{array}{l}2310 \\
6343 \\
2498\end{array}$ & $\begin{array}{l}4125 \\
1218 \\
4410\end{array}$ \\
\hline
\end{tabular}

Of course Walther, as well as the other observers men tioned, regard the adaptation as determined by the stimulation of special nerve endings in the mucous membrane by each constituent of the food, a conclusion hardly borne out by the results just quoted. Another disturbing factor in these experiments is the large variation in total quantity of juice secreted with different food-stuffs.

TABLE II.-Amount of Pancreatic Juice Secreted for different Food-stuffs (Walther).

\begin{tabular}{|c|c|c|c|c|c|c|c|c|c|c|}
\hline \multirow{2}{*}{ Food } & \multicolumn{9}{|c|}{ Hours of secretion } & \multirow{2}{*}{$\begin{array}{c}\text { Total } \\
\text { amount }\end{array}$} \\
\hline & I & 2 & 3 & 4 & 5 & 6 & 7 & 8 & 9 & \\
\hline $\begin{array}{l}\text { 600 c.c. milk } \\
250 \text { grams } \\
\text { bread } \\
\begin{array}{c}\text { Ioo grams } \\
\text { meat }\end{array} \ldots\end{array}$ & $\begin{array}{c}8 \cdot 2 \\
35 \cdot 5 \\
45^{\circ} \circ\end{array}$ & $\begin{array}{c}6.0 \\
47^{\circ} \circ \\
52 \cdot 0\end{array}$ & $\left|\begin{array}{c}23.0 \\
20.5 \\
35 \circ\end{array}\right|$ & $\begin{array}{c}6.2 \\
16.5 \\
9.75\end{array}$ & $\mid \begin{array}{c}1 \cdot 75 \\
10 \cdot 0 \\
-\end{array}$ & $\begin{array}{c}- \\
12 \cdot 0 \\
-\end{array}$ & $\begin{array}{c}- \\
6 \cdot 5 \\
- \\
-\end{array}$ & $\begin{array}{l}3 \cdot 0- \\
-- \\
-\end{array}$ & $\begin{array}{l}-1 \\
-1 \\
-14\end{array}$ & $\begin{array}{l}45 \text { c.c. } \\
\text { I } 5 \text { I, } \\
\text { I42, }\end{array}$ \\
\hline
\end{tabular}

The quantity of juice secreted will depend on the amount of secretin turned into the circulation, and this, in its turn, on the amount of acid entering the duodenum from the stomach. The amount of juice will, therefore, be measured by the stay and resistance to digestion of the substance in the stomach rather than to any direct nervous or other influence of the duodenal contents on the pancreas. A repetition of Walther's experiments by Popielski (Centralblatt f. Physiologie, vol. xvii,, 1903), working independently, has in fact led the latter to deny altogether the adaptation of the pancreatic juice to the nature of the food. Popielski concludes from his experiments that variations in the juice depend only on the intensity and duration of the stimulus, the intensity of the stimulus determining the amount of enzymes, whilst its duration determines the total quantity
of juice.

In the meantime the question had been attacked from another side. It had been shown by Fischer and Niebel (Sitzungsberichte der K. Preuss. Akad. d. Wiss., 1895, p. 73 ), as well as by Portier (C. R. Soc. de Biologie, 1898, p. $3^{8} 7$ ), that watery extracts of the pancreas of the cow, horse, and dog had no influence on lactose. Weinland in 1899

NO. I $80_{3}$, VOL. 70$]$ confirmed these results so far as concerns the pancreas of dogs on an ordinary diet free from milk. On the other hand, he found that extracts of the pancreas of dogs, which had been fed for several days on milk, sometimes with the addition of lactose, invariably contained lactase in considerable amount, and these results have been confirmed lately by Bainbridge working in our laboratory. Here then we have a definite instance of adaptation of the pancreas, the pancreatic juice or pancreatic extracts of dogs on normal diet containing no lactase, while the administration of lactose to these animals causes the appearance of lactase in both cases. Since in this case we have to determine, not simply an increase or diminution in the amounts of ferments always present in the juice, but the presence or absence of a definite substance, this was evidently the best starting point for an investigation of the mechanism by which the pancreas can adapt itself to the nature of the food, an investigation which has been carried out and completed by Dr. Bainbridge.

What are the limiting conditions? In the first place the reaction is absolutely specific. Unless the animal is taking lactose in its diet no lactase is ever found in the pancreas or in its secretion. The pancreas of new-born animals, for instance, is quite free from lactase, which, however, makes its appearance two or three days after birth as the result of the milk diet. The production of lactase is not a direct reaction of the pancreas to the presence of lactose in the blood, since subcutaneous or intravenous injection of lactose does not cause the appearance of lactase in the pancreas. The intestinal mucous membrane of all animals, whether on a milk diet or not, contains lactase and has an inverting action on lactose. It might be thought therefore that the production of lactase by the pancreas was a reaction to the presence of the products of inversion of lactose in the blood. This was found not to be the case. Subcutaneous injection of galactose for several days was not followed by any appearance of lactase in the pancreas or its juice. Nor was the appearance of lactase due to the increased production of this ferment in the mucous membrane, and its escape into the blood. Injection of an extract of mucous membrane rich in lactase, repeated several days in succession, was not followed by any appearance of lactase in the pancreas. Injection of lactose into the duodenum, and the subsequent injection of secretin after an interval of one hour, was inefficacious in causing the appearance of lactase in the pancreatic juice. For the production of lactase in the pancreas, or its juice, it is therefore necessary that lactose should act on the intestinal mucous membrane for some time. The reaction is a slow one, like the adaptation in Vasilieff's experiments, and is certainly not due to the stimulation of certain nerve endings in the mucous membrane by the lactose.

The problem was somewhat similar to that presented by the action of acid in the duodenum, since this introduced into the duodenum produces secretion of juice, whereas, when introduced into the blood stream, it has no effect whatever on the pancreas. The question suggested itself whether, under the influence of lactose, a special secretin was formed in the intestinal mucous membrane which, on access to general circulation, evoked the formation and secretion of lactase by the pancreas. Secretin was therefore made in the usual way (i.e. acidification, boiling, neutralisation, and filtering) from the mucous membrane of milk-ferl dogs. The secretion evoked by the injection of this liquid resembled that obtained from the injection of ordinary secretin, and contained no lactase.

Yet it was evident from the results already obtained that lactose must act on the pancreas through the mucous membrane of the intestine. An extract was therefore made from the mucous membrane of the whole small intestine of a milk-fed dog. This was filtered through muslin, and about to c.c. injected subcutaneously into a biscuit-fed dog once a day for three days. The dog was then anæsthetised, a cannula placed in its pancreatic duct, and ordinary secretin injected. A flow of pancreatic juice was obtained, and this juice was found to contain lactase. This experiment was performed eight times, and in each case the juice obtained from a biscuit-fed dog which had been injected with an extract of the mucous membrane of a milk-fed dog contained lactase. 
TABLE III.-Effect on Milk Sugar of Pancreatic Juice from "Biscuit-fed" dogs, which had received Subcutaneous Injections during three days of Extracts of the Mucous Membrane of "Milk-fed" dogs.

The figures represent c.c. of lactose solution which reduced 5o c.c. Pavy's solution.

\begin{tabular}{|c|c|c|c|c|}
\hline \multirow{2}{*}{ Exp. } & \multicolumn{2}{|r|}{ Controls } & \multirow{2}{*}{$\begin{array}{c}\text { Lactose }+ \text { pancreatic } \\
\text { juice }\end{array}$} & \multirow{2}{*}{$\begin{array}{l}\text { Percentage } \\
\text { of } \\
\text { inversion }\end{array}$} \\
\hline & $\begin{array}{l}\text { Solution of } \\
\text { lactose }\end{array}$ & $\begin{array}{c}\text { Lactose + pancreatic } \\
\text { juice (boiled) }\end{array}$ & & \\
\hline I $\ldots$ & $7 \cdot 4$ & $\ldots$ & $6 \cdot 8$ & I $8 \cdot 1$ \\
\hline $2 \ldots$ & $8 \cdot 2$ & $8 \cdot 2$ & $7 \cdot 6$ & $16 \cdot 5$ \\
\hline $3 \ldots$ & $8 \cdot 2$ & $8 \cdot 15$ & $7 \cdot 85$ & $9 \cdot 7$ \\
\hline $4 \ldots$ & $7 \cdot 95$ & 79 & $7 \cdot 65$ & $8 \cdot 5$ \\
\hline $5 \ldots$ & $7 \cdot 8$ & . & $7 \cdot 5$ & $8 \cdot 8$ \\
\hline $6 \ldots$ & $7^{\circ} 0$ & 705 & 6.75 & $8 \cdot 1$ \\
\hline $7 \ldots$ & $4^{\circ} \mathrm{I}$ & $\ldots$ & $3 \cdot 75$ & $20 \cdot 8$ \\
\hline $8 \quad \ldots$ & $9 \cdot 25$ & $\ldots$ & 82 & $25^{\circ} 9$ \\
\hline
\end{tabular}

Here then at last we have some glimpse into the mechanism of the adaptation of the pancreas to the nature of the food. As the result of injection of lactose some substance which we may call $x$ is. produced in the mucous membrane of the small intestine. This substance is carried by the blood to the pancreas, and there slowly gives rise to the formation of lactase which is turned out in the juice when secretion is excited by the entry of acid chyme into the duodenum. We have no knowledge as yet as to the nature of this substance $x$. All we can say is that it is destroyed at a boiling temperature, since boiled extracts of the mucous membrane of milk-fed dogs do not, when subcutaneously injected, cause the appearance of any lactase in the pancreatic juice of biscuit-fed dogs.

Whether the qualitative adaptation of the juice in respect of its trypsin, amylopsin, and steapsin is carried out in a similar fashion we cannot as yet say. We hope that an investigation of the mechanism of this adaptation, which is now proceeding, may throw light, not only on the factors involved, but also on the nature of the substance which is formed in the mucous membrane, and has this marked effect on the activity of the pancreatic cells. Involving, as it does, two distinct sets of cells, this chemical adaptation is more complex than any yet investigated, and shows the intimate relation which must exist between the chemical activities of very different organs of the body.

\section{THE ROYAL SOCIETY CONVERSAZIONE.}

THE Royal Society conversazione was held in the rooms of the Society at Burlington House on Friday last, May I3. Many exhibits illustrating methods and results of recent scientific progress were on view, and are briefly described in the following abstract of the official catalogue. So far as possible the exhibits representing related subjects are here grouped together.

In the course of the evening, lantern demonstrations were given in the meeting room of the society. Prof. W. A. Herdman gave an account of the recent investigation of the Ceylon pearl fisheries; Mr. Francis Fox showed lantern slides, illustrative of (I) operations at the Simplon Tunnel : (2) the Victoria Falls and gorge of the River Zambesi, and proposed bridge; and the Hon. C. A. Parsons, F.R.S., gave a demonstration of the auxetophone. This instrument is an air operated valve which is used for a reproducer in gramophones and phonographs, and replaces the usual reproducing diaphragm in such machines. The application of this valve to the violin was shown, selections of music, vocal and instrumental, being played on the auxetophone.

The following is a classified list of the other exhibits :-

The differentiator, a machine recording as a curve the values of the rate of change of any variable quantity which can be represented by a curve: Dr. J. Erskine-Murray. When the machine is guided along any curve it autoNO. I803, VOL. 70] matically traces another which represents the rate of change of the quantity represented by the first curve. Thus, if the population of a country at various dates be plotted on paper the derived curve shows the rate at which the population is increasing or decreasing at every date during the period chosen.-Twin-elliptic figures showing change of phase in one or both ellipses: Mr. Joseph Goold.-A radial areascale: Mr. R. W. K. Edwards. A contrivance for finding the area of a plane figure by means of a transparency.

Sensitive barograph, for the study of minor variations of atmospheric pressure: Dr. W. N. Shaw, F.R.S. The instrument shows the details of comparatively rapid fluctuations of pressure such as are often indicated in the barometric diagram of the Times.-(I) Traces obtained from self-recording instruments sent up by means of kites, (2) self-recording instruments from which the traces were obtained: Mr. W. H. Dines. In the recording instruments designed by $M$. Teisserenc de Bort, the height is obtained from an exhausted aneroid box, and the temperature from a Bourdon tube. In the recording instruments designed by the exhibitor, the height is obtained from a fair sized aneroid box of thin metal containing air. A temperature correction is necessary, but the position of the pen is dependent on the elasticity of the enclosed air.-Photographs of clouds : Commander D. Wilson-Barker.-Models and photographs of large hailstones: the Royal Meteorological Society.

Photographs and diagrams illustrating solar and meteorological changes, and a series of photographs to determine the relative temperatures of the stars: Sir J. Norman Lockyer, K.C.B., F.R.S. The exhibit illustrated (I) enlarged pictures of the sun in " $K$ " light taken with the spectroheliograph of the Solar. Physics Observatory. (2) The results of a discussion of sun-spot distribution. (3) The relationship between the positions of solar prominences and the different forms of the corona. (4) The different types, and their distribution, of the short period barometric pressure variation over the earth's surface. (5) The close connection between the change of barometric pressure and rainfall. (6) Series of photographs taken with a quartzcalcite prismatic camera of 2 inches aperture and 18 inches focal length to determine the relative temperatures of stars. -The Narraburra siderite, New South Wales: Prof. A. Liversidge, F.R.S. This exhibit included photographs of the siderite, and photographs of etched sections to show the changes in the internal structure. The composition of the siderite was :-iron 88.605 , nickel $9.74 \mathrm{I}$, cobalt 0.474 , copper 0.009 , phosphorus 0.429 , sulphur traces, resinous matter 0.008 , insoluble in $\mathrm{HCl} .0 .720=99.906$. Traces of gold and of the platinum metals appeared also to be present.-Transparencies and prints in illustration of a photographic atlas of the heavens; photographed at the Royal Observatory, Cape Town, 1903-4: Mr. J. Franklin-Adams.-Ten transparencies from negatives taken with the Rumford spectroheliograph of the Yerkes Observatory by Prof. G. E. Hale and Mr. F. Ellerman : the Royal Astronomical Society.

Examples showing the application of natural colour photography to the production of lantern slides of spectra for lecture and educational purposes : Mr. E. Sanger-Shepherd. Negatives are taken through three colour filters, admitting light of the three primary colour sensations-red, green and blue-violet, in accordance with the power of the respective sensations to excite the eye. From these negatives gelatin relief prints are made upon a special film, each relief being soaked in a water-colour ink of the complementary colour to the sensation which it represents. These reliefs whilst still wet are successively applied to a mordanted gelatinised glass plate. The inks transfer to the mordanted gelatin film, and the result is a natural colour photograph, consisting of nothing but the colouring matter securely locked up in a single film of gelatin.-Colour photographs shown by spectrum colours: Sir W. de W. Abney, K.C.B., F.R.S. The ordinary three-colour photographs are shown in a triple lantern, one image being tinted by the light coming through red glass, another by that through green glass, and the third by that through blue glass. The new method substitutes spectrum colours for the three glasses, with the result that the colours on the screen are much purer and truer.--High power. microscopy: Mr. J. W. Gordon. The apparatus consists of a compounding drawtube and oscillating screen, as proposed in Mr. J. W. Gordon's paper on the Helmholtz 